\title{
Enriching Conflict Resolution Environments with the Provision of Context Information
}

\author{
Davide Carneiro, Marco Gomes, Ângelo Costa, Paulo Novais, José Neves \\ CCTC/Department of Informatics \\ University of Minho, Braga, Portugal \\ \{dcarneiro, pjon, acosta, jneves\}@di.uminho.pt,pg18373@alunos.uminho.pt
}

\begin{abstract}
It is a common affair to settle disputes out of courts nowadays, through negotiation, mediation or any other mean. This has also been implemented over telecommunication means under the so-called Online Dispute Resolution methods. However, this new technology-supported approach is impersonal and cold, leaving aside important issues such as the disputants' body language, stress level or emotional response while being based on forms, e-mails or chat rooms. To overcome this shortcoming in this paper it is proposed the creation of intelligent environments for conflict resolution that can complement the existing tools with important knowledge about the context of interaction. This will allow decisionmakers to take better framed decisions based not only on figures but also on important contextual information, similarly to what happens when parties communicate in the physical presence of each other.
\end{abstract}

Keywords: Affective Computing, Role Playing Games, Emotions, Ambient Intelligence, Conflict Resolution Environments.

\section{Introduction}

The increase in the transaction volume of global B2C e-Commerce led to a whole new way of doing commerce globally. Now, we talk of electronic contracting performed in part or wholly by means of electronic agents. However, disputes are still likely to arise in these transactions, namely because of late shipments or products of low quality. Courts, that were shaped after the industrial era and are still paper-based, are not ready for both the amount and the new characteristics of these disputes. The immediate consequence is an increase in the waiting queues of courts, rendering judicial systems slow and unresponsive.

In a first attempt to address this problem, several alternatives to litigation in courts started to be adopted in the last decades - the so called Alternative Dispute Resolution (ADR) methods, including negotiation, mediation or arbitration (Brown and Marriot 1999). With the advent of the Information Society, these 
techniques started to be implemented in virtual environments as well, leading to what is today known as Online Dispute Resolution (ODR) (Katsch and Rifkin 2001). In its most basic form, Online Dispute Resolution simply implements already traditional methods over a communication mean, i.e., instead of negotiating in person, the disputant parties do it over a phone line or a similar mean. However, the latest research trends show that the role of technology in dispute resolution can be further enhanced, namely by using techniques from Artificial Intelligence (Lodder and Thiessen 2003). In such ODR systems, technology is used not only to put parties into contact but also to suggest solutions, plan strategies or compile useful information.

However, this approach still has some flaws. Namely, when parties use an online tool, a significant amount of important information is lost. This information includes body language, context information or emotional state. All this would be taken into account by a judge or a jury in a litigation in court in a decision making process (Damásio 1994), even if in an unconscious way, but is lost when using an ODR tool. Its main usefulness is in determining how each aspect of the dispute resolution process affects each party (e.g. is the party happy with the proposed solution?, does the party fill threatened when talking to the other party?, is the party nervous when addressing a specific issue?).

The lack of contextual information that would allow parties to take better decisions is thus due to the low richness of the media used to communicate, mostly text-based. In fact, it results difficult to convey emotions and other aspects of our rich communication processes using text only, something that we do intuitively and unconsciously when we are face-to-face.

The development of ODR systems that are indeed able to perceive the state of the parties is thus of the utmost importance (Friedman and George 1997). The challenge addressed in this paper is thus the one of acquiring the necessary information to perceive this state.

The use of soft computing techniques can be the answer to this challenge. Indeed, this field has been used recently to address a wide range of different realworld problems (Sedano et al. 2010; Corchado et al. 2010; Corchado et al. 2012; Zargari et al. 2012). Therefore, in this paper, a novel approach on ODR research is presented, merging different concepts: Ambient Intelligence (AmI), Role-Playing Games (RPG), Emotions, Conflict Handling Styles and Stress. Our objective is to build a knowledge environment that can be used by decision-makers to take more realistic and better framed decisions in a legal context.

Ambient Intelligence is a recent technological paradigm in which traditional environments are empowered with the objective of providing useful context-aware services (Aarts and Grotenhuis 2011). This paradigm establishes the framework and the key ideas for a dynamic knowledge environment supporting the integration of the different concepts described next.

Role-Playing Games are a type of game in which players "interpret” a character created in a given scenario (environment), allowing to create "social laboratories" (Nick 2003; Barreteau et al. 2003). To represent emotions the models proposed by William James (James 1884) and Carl Lange (Lange 1967) will be followed. This 
theory suggests that emotions are the result of a response of human physiological external stimuli, i.e., every emotion is associated with a different physiological response (Cannon 1927). Conflict handling styles depict the way that each one of us reacts before a conflict scenario in terms of assertiveness and cooperativeness. Finally, stress has also a significant influence on our activities and, while a controlled level may even be positive in the generation of ideas and taking of decisions, an increased level of stress may jeopardize the whole process and damage future relationships.

The approach presented in this paper develops around the idea of an intelligent environment for supporting conflict resolution, in which the evaluation of the context of interaction of the parties is an important step for efficiently achieving a mutually satisfactory outcome. Our vision is that parties can be in their own environments, using an ODR tool to solve a conflict, with the respective environments collecting important information and sharing it with the dispute resolution tool. To materialize it, this work brings together two projects: VirtualECare and UMCourt.

\section{Bridging Ambient Intelligence and Online Dispute Resolution}

UMCourt and VirtualECare are two research projects maintained by the Intelligent Systems Lab, at the University of Minho. The VirtualECare project (Costa et al. 2008; Costa et al. 2009) focuses on the Ambient Intelligence paradigm and has as main objective to develop an agent-based environment able to monitor, interact and provide its customers with services to support daily living. Moreover, this project also focuses on the acquisition of data for supporting high-level decision making. In that sense, the system is able to read environmental and contextual information from its user's environment, including environmental conditions, emotional state or physiological state. VirtualECare's architecture (Figure 1) is a distributed one, bringing together two technologies: OSGi and Jade (Open Services Gateway Initiative, 2003; Bellifemine et al. 2007).

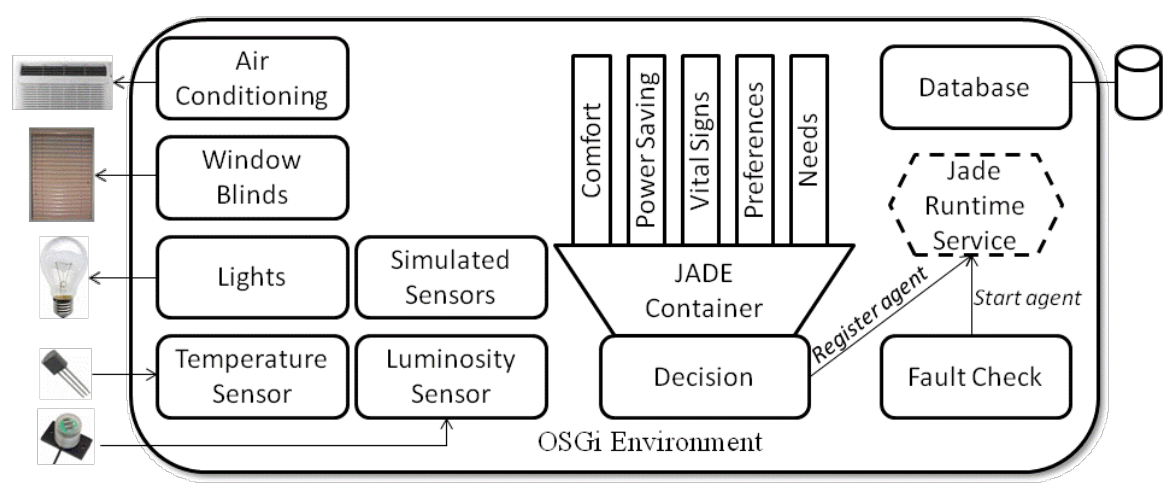


Fig. 1. A simplified view of the VirtualECare architecture.

OSGi services are used to connect software agents and devices, hiding their singularities and allowing their functionalities to be accessed as standard services. Jade agents, on the other hand, are in charge of all the analysis and decisions making processes. VirtualECare also implements an OSGi-based fully functional simulation platform that allows for the creation and study of specific scenarios. All the data generated, either by an actual implementation of the system or by the simulation platform, is available to external applications by means of OSGi services.

UMCourt, on the other hand, is a conflict resolution platform being developed under the TIARAC funded project that aims at the development of a multi-faceted agent-based ODR architecture, suited to be used in different legal domains (Andrade et al. 2010). The main objective is to empower the role of the parties in the dispute resolution process by providing meaningful and contextualized information, proposing solutions, strategies and guidance by means of mediation and negotiation algorithms. Similarly to VirtualECare, this architecture (Figure 2) is also based on OSGi and Jade. This allowed these two projects to come together, laying the path to a new research direction: Dispute Resolution Environments. A detailed description of the architecture and the implemented services is given in (Carneiro et al. 2010b; Carneiro et al. 2009).

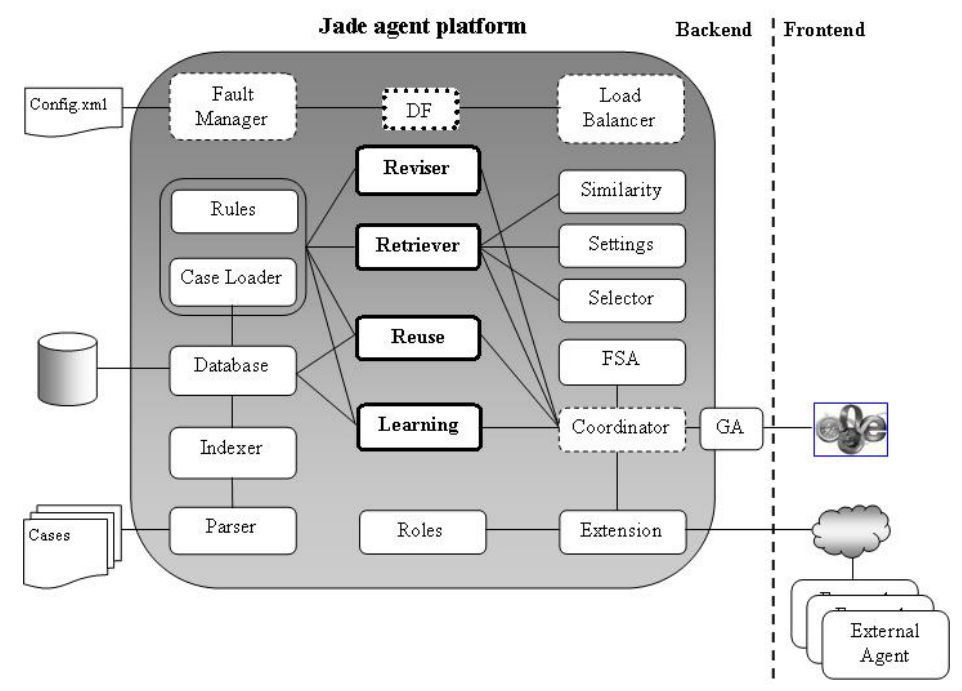


Fig. 2. The organization of the agents that make up the UMCourt architecture.

\section{Intelligent Environments Supporting Conflict Resolution}

Intelligent Environments can improve conflict resolution processes in many different ways. Specifically, different ways in which IEs can be used to provide different types of context information have been explored, to enrich the knowledge available for decision-making. Some of the approaches presented in this section are working implementations while others are simulations that allow us to improve the models used before their actual implementations.

Two different high-level trends are presented in this paper. On the one hand two solutions that are already implemented and working as modules of the UMCourt conflict resolution platform will be detailed. These modules are described in subsections 3.1 and 3.2. The first classifies the conflict resolution style of the parties in real time by analyzing the proposals exchanges against boundary values defined in legal documents. The second assesses the level of stress of users based on their interaction patterns with the devices used as interfaces. Both are performed in a non-intrusive way and provide very important knowledge about the context of interaction to the mediator and to the conflict resolution platform itself.

In the second trend the VirtualECare simulation platform is being used to generate knowledge that can be important for the decision-making processes. Simulation is paramount when it comes to create critical real-world scenarios where the margin of error must be minimal. The VirtualECare simulation tool is used to generate information about the parties, their context and their emotional state. The interest lies on the study of the effect of this information on the automated decision-making processes of UMCourt and assess their actual value for a human mediator.

The tool allows simulating one instance of an intelligent environment setting, fully configurable in terms of devices, rooms, physical properties, user's actions, internal and external atmospheric conditions, among others. This means that the tool allows simulating specific sensors such as temperature or humidity sensors but also vital sign ones. Given the scope of this work, focus will be on the simulation of the emotional state of the parties as an input for UMCourt. Our main aim is that either UMCourt or the mediator can take better decisions by encompassing knowledge about the emotional state of the parties, allowing to adapt and fine-tune strategies in real time. There is also interest in the possibility of creating user groups, based on role-playing games, in which each player can embody a certain character, with a given role and permissions (e.g. mediator, plaintiff, defendant, neutral). This is very important in a legal context since each person has different objectives (which have influence over parameters such as the conflict resolution style or the level of stress). Our objective in the long term is to replace these simulated sensors by real ones, in order to implement an actual 
dispute resolution environment able to compile all this important information, similarly to what has already been done with the stress estimation and the conflict resolution style classification.

In subsections 3.3 and 3.4 two components of the simulation platform are detailed that allow simulating important user's parameters: the personality traits and the emotions. The simulation of these parameters is important to train and assess the behavior of the conflict resolution platform, allowing to understand how it would behave if actual information about the real users was being used.

\subsection{Classification of the Conflict Resolution Style}

In alternative conflict resolution processes in which humans have a preponderant role, specifically in negotiation and mediation, the style of dealing with the conflict of each party will certainly influence the course of action and, consequently, the outcome. In this line of work focus is placed on developing methods for classifying the conflict resolution style of a person in a non-intrusive way, i.e., without using the traditional self-report instruments (such as questionnaires) with all its known disadvantages and inaccuracies. Kenneth Thomas and Ralph Kilmann formalized the way we respond to conflict situations into five different modes in terms of individual's assertiveness and cooperativeness (Thomas and Kilmann 1974). The authors defined five different conflict handling styles: competing, accommodating, avoiding, collaborating and compromising.

While the authors used a questionnaire that parties should fill in order to determine their conflict handling style, a different approach was followed. The interactions between the parties are analyzed in real time in order to estimate their style by analyzing the proposals exchanged while negotiating. This analysis is performed based on economical concepts, adapted to the legal domain. Specifically, to correctly analyze each proposal, we need to be aware of the BATNA and WATNA (respectively Best and Worst Alternative to a Negotiated Agreement) (De Vries et al. 20) which indicate the best and worst scenarios possible by law. The ZOPA - Zone of Potential Agreement is also taken into account (Raiffa 1982), as well as the the MLATNA - Most Likely Alternative to a Negotiated Agreement (describing the most likely scenario from a legal point of view) (Steenbergen 2005). 


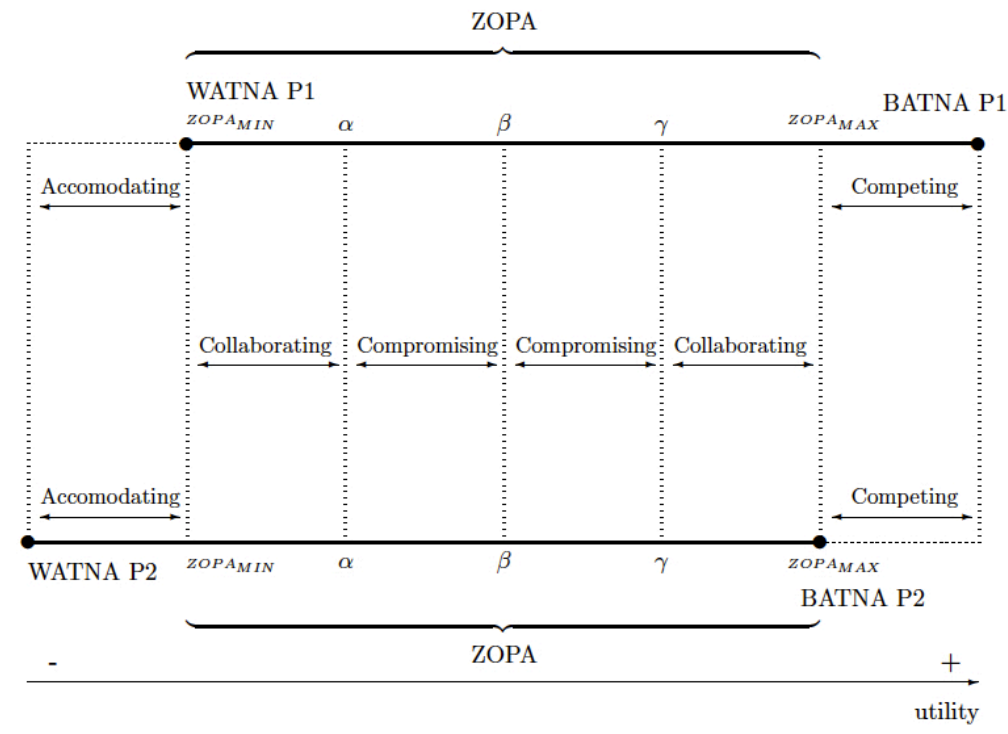

Fig. 3. The space that defines the personal conflict styles in function of the utility of the proposals and the values of the BATNA, BATNA and ZOPA.

Generally, a negotiated process goes on with the parties exchanging successive proposals until they agree on a specific one or someone exits the process. The conflict handling style can be estimated by analyzing the proposals exchanged according to the intentions and objectives of the parties and also according to the space defined by the BATNA and WATNA of each party (Figure 3).

In each round, each action of a party will contribute to the overall characterization of his conflict handling style. Thus, the conflict handling style is a continuous process, not defined by a single interaction but by a continuous analysis of the evolution of the interactions. In each round, two main paths are possible: either the party ignores the proposal or the party answers to the proposal. When a party ignores a proposal, he is exhibiting an Avoiding behavior given that he is satisfying neither his interests nor the ones of the other party.

On the other hand, when the party makes a proposal or a counterproposal, he is cooperating on the process. However, in order to be more precise, the nature of the proposal must be analyzed. Our approach consists in analyzing each proposal in terms of its utility for each party. This analysis is subject to a set of principles.

If the utility of the proposal is higher than the BATNA of the other party, he is showing a Competing style. In fact, the party is trying to maximize his own gain, probably in an unrealistically way, completely disregarding the other party.

If the utility of the proposal is lower than the WATNA of the other party, the party is neglecting his own gain or even maximizing the gain of the other party. This may happen when a party is not aware of his chances, is facing a party with a relationship of power or just wants to end the process quickly. In such a scenario, the party is assumed to be exhibiting an Accommodating behavior. 
When the utility of the proposal falls within the range of the ZOPA, it indicates that the party is being reasonable and trying to propose a settlement in which both parties will not win everything but will not lose everything either. In such a scenario, the conflict style is determined according to the distance to the average point of the ZOPA, as defined in equation 1.

$$
\beta=\left(\frac{Z O P A_{M I N}+Z O P A_{M A X}}{2}\right)
$$

Two points are defined that allow classifying the remaining conflict styles, as depicted in equations 2 and 3.

$$
\begin{aligned}
& \alpha=\left(Z O P A_{M I N}+\frac{\beta-Z O P A_{M I N}}{2}\right)=\left(\frac{Z O P A_{M I N}+\beta}{2}\right) \\
& \gamma=\left(Z O P A_{M A X}-\frac{Z O P A_{M A X}-\beta}{2}\right)=\left(\frac{Z O P A_{M A X}+\beta}{2}\right)
\end{aligned}
$$

When the utility of a proposal falls within the range defined by $[\alpha, \gamma]$, the proposing party is negotiating in an intermediary area of the ZOPA. This denotes that the party is trying to reach a compromise with potential losses in both sides. The party is thus evidencing a Compromising behavior.

On the other hand, if the value of the utility is in the range defined by $\left[Z O P A_{M I N}, \alpha[\cup] \gamma, Z O P A_{M A X}\right]$, the party is proposing a solution closer to the limits of the ZOPA. This may indicate a party that is trying to work out a mutually agreeable solution, but trying to explore the weaknesses of the opposing party, trying to force him to accept it using some position of power. The conflict style of the party is this way defined as Collaborating.

However, it is common that people do not make use of a single conflict style at a time. Moreover, people often change their conflict style according to the evolution of the process. In that sense, a more precise approach is proposed in which a main conflict style is inferred, together with a trend style. This indicates that a party shows a given style with a possible tendency towards another one. The following notation is used to denote a main conflict style with a trend to a secondary one: Main $\rightarrow$ secondary.

Let $\varphi$ be the value of the utility of a proposal. The following personal conflict handling styles are defined:

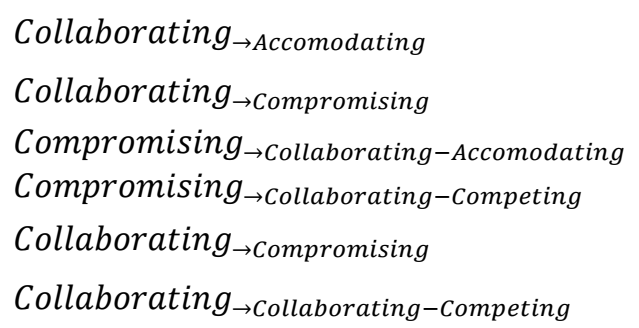

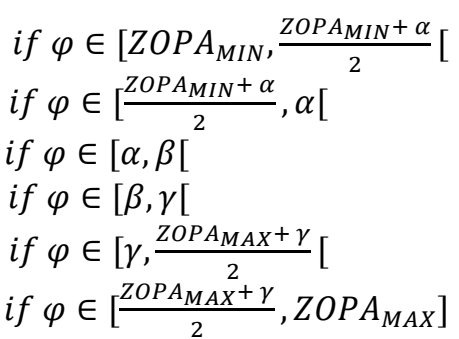


Performing this classification in each round of the process allows the mediator/negotiator to build a notion of the evolution of the conflict handling style of each party (Figure 4). With this knowledge, the neutral party will be able to determine the best moments to interfere in the process in an attempt to maximize the success of the outcome.

\subsection{Assessment of the Stress Level}

Similarly to the conflict handling style, stress has a significant influence on the decisions taken during a negotiated process. In fact, stress has an influence (positive or negative) on virtually every decision we take. One of the first definitions of stress was proposed by Selye (1956). According to the author, stress can be seen as a non-specific response of the body to external demands. These demands (the load or stimulus that triggered a response) are denominated stressors while the internal body changes that they produce constitute the actual stress response.

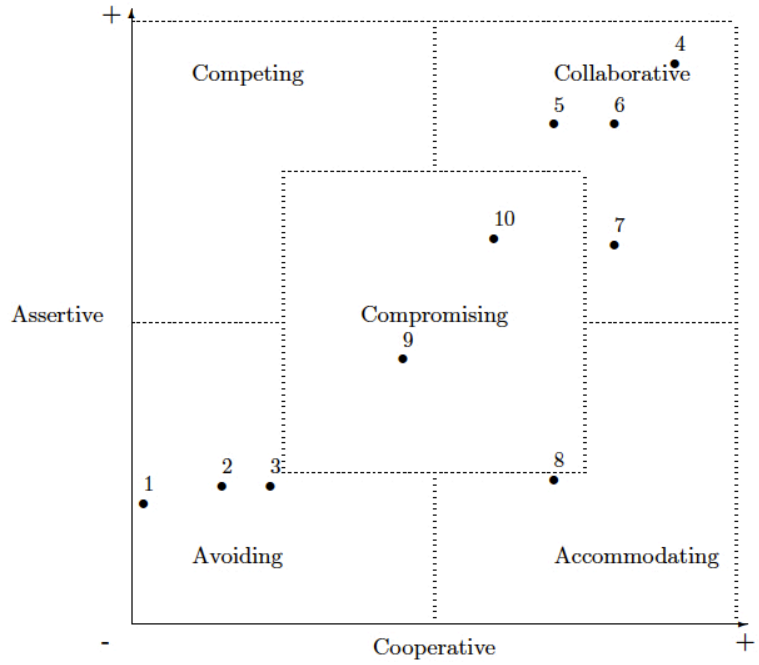

Fig. 4. The evolution of the conflict style of a party in 10 rounds.

In a traditional conflict resolution setting in which all the intervenient parties gather in the physical presence of each other, evaluating the stress level is more or less natural for us: we do it by analyzing the body language and the effects of stress on the body and mind of our interlocutors, in an almost innate way. However, doing it over a virtual communication channel in which all this accessory information is lost results almost impossible. This constitutes a 
significant obstacle to effective communication and jeopardizes the ability of the negotiator or mediator to take good decisions.

In this line of work focus is placed on estimating the level of stress of the users in a non-intrusive and transparent way and providing this information to support decision making, ultimately contributing to more satisfactory and successful outcomes. Similar approaches can be found in the literature, despite in different fields. (Healey and Picard 2005) analyze the level of stress of the drivers of vehicles, although in an invasive way, whereas in (Vizer et al. 2009), detection of stress is performed using keystroke and linguistic features.

In order to develop this model, an experiment was set up whose objective was to determine the effects of stress on behavioral, physical and cognitive parameters. In that sense, a game involving mental calculations and memorization was developed to be played on devices equipped with a basic set of sensors. The devices used to implement the experiment are depicted in Figure 5 and briefly described in Table 1.

Table1. Brief description of the devices used to implement the experiment.

\begin{tabular}{|l||l|l|}
\hline Device & Brief description & Main features \\
\hline HP Touchsmart & All-in-one PC & $\begin{array}{l}\text { touchscreen, web cam, large } \\
\text { screen }\end{array}$ \\
\hline $\begin{array}{l}\text { Samsung } \\
\text { Galaxy Tab }\end{array}$ & Tablet PC & $\begin{array}{l}\text { touchscreen, web cam, ac- } \\
\text { celerometer, relatively large } \\
\text { screen, mobile, Android OS }\end{array}$ \\
\hline HTC PDAs & Smartphones & $\begin{array}{l}\text { touchscreen, camera, ac- } \\
\text { celerometer, mobile, Android } \\
\text { OS }\end{array}$ \\
\hline $\begin{array}{l}\text { Sony FCB- } \\
\text { EX780BP }\end{array}$ & $\begin{array}{l}\text { 25x Super HAD PAL } \\
\text { Color Block Camera } \\
\text { with External Sync }\end{array}$ & $\begin{array}{l}\text { 25x Optical Zoom, Image sta- } \\
\text { bilizer, Day/Night Mode, Pri- } \\
\text { vacy Zone Masking }\end{array}$ \\
\hline
\end{tabular}

The participants of the experiment played this game in two different phases. In a first one, the participants would do it without any stressors, with all the time and quietness to think carefully on their decisions. In a second phase, the same participants played the same game but this time subject to stressors such as time constraints, vibrations on the device, annoying and unexpected sounds, among others. The main objective of the experiment was to determine, for each user, which of the studied parameters was affected by stress and in which measure. 

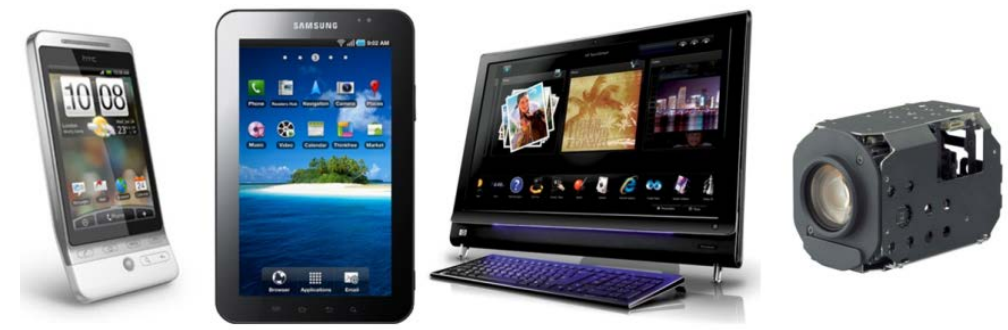

Fig. 5. Devices used in the experiment to collect data about interaction and movement patterns.

The parameters considered were as follows:

- Touch pattern - the touch pattern represents the way in which a user touches the device and represents a variation of intensity over a period of time. This information is acquired from touchscreens with support for touch intensity.

- Touch accuracy - a comparison between touches in active controls versus touches in passive areas (e.g. without controls, empty areas) in which there is no sense in touching. This information is acquired from touchscreens.

- Touch intensity - the intensity of the touch represents the amount of force that the user is putting into the touch. It is analyzed in terms of the maximum, minimum and mean intensity of each touch. This information is acquired from touchscreens.

- Touch duration - this represents the time span between the beginning and the end of the touch event. This data is acquired from devices with touchscreens.

- Amount of movement - the amount of movement represents how and how much the user is moving inside the environment. An estimation of the amount of movement from the video camera is built. The image processing stack uses the principles established by Castillo et al. (2011) and uses image difference techniques to calculate the amount of movement between two consecutive frames (Fernández-Caballero et al., 2010).

- Acceleration - the acceleration is measured from accelerometers in mobile devices. It is useful for building an estimation of how much the user is moving and how he is doing it (e.g. is the user having sudden movements?). Moreover, information from the accelerometer is used to support the estimation of the intensity of touch.

With data about this parameters for each user and for each scenario (stress/no stress), significance tests were performed to determine, to which extent, each user was affected by stress in each parameter. This supported the development of personalized stress models based on the way users interact with the technological 
devices and on the way they move. The whole experiment is described in detail in (Careiro et al. 2012).

These stress models allowed us to develop a real-time solution for assessing the level of stress of users. It is non-intrusive since it is based solely on the analysis of the users' interaction patterns. It is reliable since these interaction patterns are hard to fake, are innate and we exhibit them without planning them or thinking about them. It is also transparent: it can be used in conjunction with any application running on a handheld device and provide information about the stress level of the user to a server.

The information compiled about stress includes not only the estimated level of stress but also the contribution of each of the parameters for the levels of stress (e.g. some parameters are more affected than others for given users, thus have different weights). Finally, it also provides a measure of the quality of information given in terms of the number and type of inputs available. In fact, there are moments in which there will be no data for a given input (e.g. in the last seconds the user did not touch the screen). The application can still provide a value of stress based on the other parameters (e.g. accelerometer, amount of movement), although with an expected smaller accuracy. The quality of information quantifies the accuracy of this estimation based on which parameters are available and on the results of the tests of significance (a parameter that has shown significant differences in the tests will provide more reliable information on stress than a parameter that has shown small differences).

This transparent stress estimation layer allows for a mediator to have knowledge about the level of stress of the parties involved in the conflict resolution, allowing him to take better decisions during the process. These decisions may include a change in the strategy, pauses in the process or interrupting direct communication between the parties. With this approach, the mediator is no longer blindly and coldly analyzing proposals from a purely economic perspective. He does it with the support of all this context information, in a way that is more similar to what is done when the parties are together in a single physical location. This will allow for better decisions and, ultimately, for better possibilities of achieving satisfactory outcomes.

\subsection{Simulation of User Traits}

One useful feature in simulation tools concerns the possibility to simulate different user-types. These types are created based on role-playing game techniques, i.e. each user-type will represent a different pre-defined role on the environment, which enables him to perform different actions or exhibit a given behaviour. Thus, the simulation platform allows defining the different actions that each role can perform in the conflict resolution environment (Figure 6). The use of role-playing game techniques permits the distinction of the different users with specific 
characteristics. It also allows to assign different conflict styles to each user group, denoting the way that each one has to deal with the conflict.

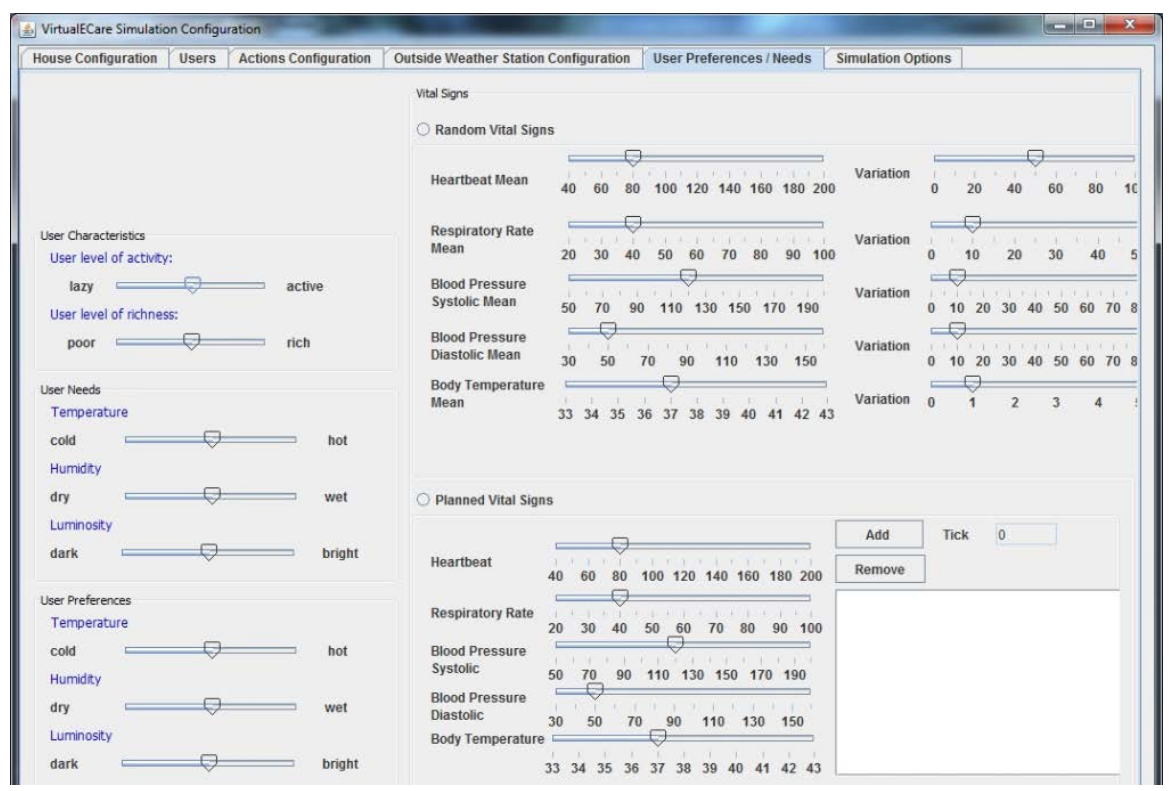

Fig. 6. A detail of the configuration of the vital signs of a given user. Vital signs can be configured to behave randomly according to a normal distribution with given parameters or they can be completely planned for the time of the simulation, allowing to plan specific scenarios.

The tool also allows simulating vital signs. These are some of the most important factors in determining the emotional state of an individual. Moreover, vital signs can also be directly related with the stress level. However, the methods for acquiring this information may be invasive and even influence the results. In that sense, for the moment, these are being simulated. The configuration of these parameters is depicted in Figure 7. By creating different vital sign configurations, one can induce specific scenarios and see how the inference mechanisms create the associated emotional state of a party and, consequently, how the UMCourt platform adapts its strategies according to it. The simulation tool allows to independently configure the vital signs of each user. Two modes are possible: Random and Planned. In Random mode, the vital signs of the different users can be configured to develop randomly, according to configurable Gaussian functions. Alternatively, in the Planned mode, these vital signs can be completely planned. This means that it is possible to configure the exact vital signs of a user in each time instant of the simulation. This allows to, for example, induce a given physiological state for a given time instant and assess how the system reacts to it. 


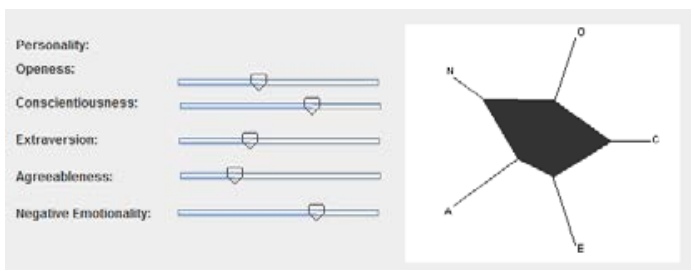

Fig. 7. A detail of the configuration of the users' personality types.

\subsection{Simulation of Emotions}

The simulation tool can also provide information regarding the emotional state of the users. In order to simulate the emotions of a user in a realistic fashion, a combined use of the user's objectives (bridging with the work described in the previous subsection), the state of the environment and the type of personality is being made. For example, if the user has as objective to maximize his personal gain at all cost and the most likely outcome of the dispute resolution process is one in which his gains are low, the simulated emotion will be between sadness and disappointment. The time that this emotion lasts as well as its intensity is determined by the personality type. To model the personality of each user the OCEAN (Openness, Conscientiousness, Extroversion, Agreeableness and Negative emotionality) model is being used (McCrae et al. 2005).

To define the emotions, a mutation of the OCC theory (Ortony et al. 1988) is being used, defined after the requirements of this specific field of application. Thus, at this moment, our emotional model considers the following basic emotions: happiness, sadness, fear, anger, disappointment and surprise. When defining this basic set of emotions, it was also considered the most suited emotions to express the opinion of the user about a suggestion or action of the system. Evidently, the same actions will trigger different emotions on different users, depending on the personality type.

Moreover, the system is able to infer the emotional state of the dispute resolution environment as the average of the emotional state of all the participants in the dispute resolution process. A graphic similar to the one shown previously in figure 7 is computed using the average values of the emotions of all the users, that allows to understand the overall state of the environment. This is useful when the system must perform an action in the common scenarios in which there is a conflict of interests. In this sense, two approaches can be followed. On the one hand, the system can be configured to satisfy the emotions of a particular user or of a user with a given role. On the other hand, the system can be configured to maximize the satisfaction of all the users in the environment.

In this case the mean of the preferences is maximized. This results interesting when we are training automated conflict resolution models to behave in ways that are similar to the ones conducted by human experts. 


\section{Conclusion and Future Work}

Current trends on ODR tools are not considering important information such as the body language or emotional states. This happens because current tools rely basically on web interfaces. In order to address this problem, a new approach is proposed, based on intelligent environments. It was argued that current tools must be complemented by environments that are able to acquire important context information about the parties and their surroundings. Using this information, ODR tools and mediators/negotiators will be able to determine to which extent a suggestion, an action or a given topic affects each party and, this way, adapt strategies in order to more efficiently achieve more mutually satisfactory outcomes.

Given the complexity of such environments, a simulation platform was used to study and assess the development of the software modules, that are then used in the actual implementation of the UMCourt conflict resolution platform. This allows us to create specific scenarios, with specific user-types and determine how UMCourt and neutrals adapt strategies accordingly (case retrieval, solution proposal, mediation and negotiation conduction).

In future work, more steps will be taken towards the actual implementation of all the modules in a real environment. This includes the acquisition of sensors that will gradually replace the sensors currently being simulated. A database of cases that store the emotional state before and after given actions taken by the ODR system is also being built. This allows us to use a nearest neighbor retrieval algorithm to examine past cases and predict, at each time and based on the conflict styles, how a given action may affect each party. This will allow the system to determine at which point a party moves from an avoiding conflict style to a compromising one (Carneiro et al. 2010a), for example. In fact, the determination of the conflict styles is a very important feature for a mediator. In future work machine learning techniques such as classification will be used in order to make the selection of cases and compare their effectiveness with the one of the retrieval algorithm. This, we believe, is the path to develop ODR tools that encompass very important context information that is being ignored by current research trends.

Acknowledgments. This work is part-funded by ERDF - European Regional Development Fund through the COMPETE Programme (operational programme for competitiveness) and by National Funds through the FCT - Fundação para a Ciência e a Tecnologia (Portuguese Foundation for Science and Technology) within project FCOMP-01-0124-FEDER-028980 (PTDC/EEI-SII/1386/2012) and PEst-OE/ EEI/UI0752/2011. The work of Davide Carneiro is also supported by a doctoral grant by FCT (SFRH/BD/64890/2009). 


\section{References}

AARTS, E. AND GROTENHUIS, F. (2011) Ambient Intelligence 2.0: Towards Synergetic Prosperity. Journal of Ambient Intelligence and Smart Environments, 3(1):3-11.

ANDRADE, F., NOVAIS, P., CARNEIRO, D., NEVES, J. (2010) Conflict Resolution in Virtual Locations. In Information Communication Technology Law, Protection and Access Rights: Global Approaches and Issues. Portela, I., Cunha, M. (Eds), IGI Global.

BARRETEAU, O., LE PAGE, C. AND D'AQUINO, P. (2003) Role-Playing Games, Models and Negotiation Processes. In Journal of Artificial Societies and Social Simulation, vol. 6, no. 2.

BELLIFEMINE, F.L., CAIRE, G., GREENWOOD, D. (2007) Developing Multi-Agent Systems with JADE, Wiley Series in Agent Technology, ISBN-13: 978-0470057476.

BROWN, H., MARRIOTT, A. (1999) ADR Principles and Practice. Sweet and Maxwell.

CANNON, W. (1927) The James-Lange Theory of Emotions: A Critical Examination and an Alternative. In The American Journal of Psychology, vol. 39, pp. 106-124.

CARNEIRO, D., NOVAIS, P., ANDRADE, F., ZELEZNIKOW, J., NEVES, J. (2009) The Legal Precedent in Online Dispute Resolution. In Legal Knowledge and Information Systems, ed. Guido Governatori, Proceedings of the Jurix 2009, pp. 47-52.

CARNEIRO, D., NOVAIS, P., ANDRADE, F., NEVES, J. (2010a) Using Mediation to Solve Disputes with Avoiding Parties. In Proceedings of the Fourth International Workshop on Juris-Informatics (Jurisin 2010), pp. 17-28.

CARNEIRO, D., NOVAIS, P., COSTA, R., NEVES, J. (2010b) Developing Intelligent Environments with OSGi and JADE, The Third IFIP International Conference on Artificial Intelligence in Theory and Practice.

CARNEIRO D., CARLOS CASTILLO J., NOVAIS P., FERNÁNDEZ-CABALLERO A., NEVES J. (2012) Multimodal Behavioural Analysis for Non-invasive Stress Detection, Expert Systems with Applications, Elsevier, http://dx.doi.org/10.1016/j.eswa.2012.05.065

CORCHADO, E., ARROYO, A., TRICIO V. (2010) Soft computing models to identify typical meteorological days. In: Logic Journal of the IGPL, Oxford University Press.

COSTA, R., NOVAIS, P., LIMA, L., CARNEIRO, D., SAMICO, D., OLIVEIRA, J., MACHADO, J., NEVES. J. (2009) VirtualECare: Intelligent Assisted Living. In Electronic Healthcare, Dasun Weerasinghe (ed.), Springer-Verlag, pp. 138-144.

CASTILLO, J.C., RIVAS-CASADO, A., FERNÁNDEZ-CABALLERO, A., LÓPEZ, M.T., MARTÍNEZ-TOMÁS, R. (2011) multisensory monitoring and interpretation framework based on the model-view-controller paradigm. In: Proceedings of the 4th International Workshop on the Interplay between Natural and Artificial Computation, vol 1, pp. 441-450.

CORCHADO, E., SEDANO, J., CURIEL, L. AND VILLAR, J. R. (2012) Optimizing the operating conditions in a high precision industrial process using soft computing techniques. Expert Systems, 29: 276-299. doi: 10.1111/j.1468-0394.2011.00588.x.

COSTA, R., CARNEIRO, D., NOVAIS, P., LIMA, L., MACHADO, J., MARQUES, A., NEVES, J. (2008) Ambient Assisted Living. In: Advances in Soft Computing, vol. 51, Springer- Verlag, pp. 86-94. 
DAMÁSIO, A. (1994) Descartes' Error: Emotion, Reason, and the Human Brain, Putnam Publishing, hardcover: ISBN 0-399-13894-3.

DE VRIES B.R., LEENES R., ZELEZNIKOW J. (2005) Fundamentals of providing negotiation support online: the need for developping BATNAs, Proceedings of the Second International ODR Workshop, Tilburg, Wolf Legal Publishers, pp. 59-67.

JAMES, W. (1884) What is an Emotion?. In: Mind, vol. 9, no. 34, pp. 188-205.

FERNÁNDEZ-CABALLERO, A., CASTILLO, J.C., MARTÍNEZ-CANTOS, J., MARTÍNEZ-TOMÁS, R. (2010) Optical flow or image subtraction in human detection from infrared camera on mobile robot. Robotics and Autonomous Systems 58 (12), 12731281.

FRIEDMAN, GEORGE H. (1997) Alternative Dispute Resolution and Emerging Online Technologies: Challenges and Opportunities, 19 Hastings Comm. \& Ent. L.J. 695.

HEALEY, J., PICARD, R. (2005) Detecting Stress During Real-World Driving Tasks Using Physiological Sensors. IEEE Transactions on Intelligent Transportation Systems, 6(2):156-166.

KATSCH E., RIFKIN J. (2001) Online dispute resolution - resolving conflicts in cyberspace. Jossey-Bass Wiley Company, San Francisco.

LANGE, C. (1967) The emotions. New york: Harner Publishing co.

LODDER, A., THIESSEN, E. (2003) The role of artificial intelligence in online dispute resolution. In Workshop on Online Dispute Resolution at the International Conference on Artificial Intelligence and Law, Edinburgh, UK.

MCCRAE, R., COSTA, P., MARTIN, T. (2005) The neo-pi-3: A more readable revised neo personality inventory. In: Journal of Personality Assessment, 84 (3):261—270.

NICK, Y. (2003) The Psychology of Massively Multi-User Online Role-Playing Games: Motivations, Emotional Investment, Relationships and Problematic Usage. In Avatars at Work and Play, Computer Supported Cooperative Work, vol. 34, pp. 187-207.

ORTONY, A., CLORE, G., COLLINS, A. (1988) The cognitive structure of emotions. University Press.

OPEN SERVICES GATEWAY INITIATIVE (2003) Osgi Service Platform, Release 3. IOS Press.

RAIFFA, H. (1982) The art and science of negotiation: how to resolve conflicts and get the best out of bargaining, Cambridge, The Belknap Press of Harvard University Press.

SEDANO J., CURIEL, L., CORCHADO, E., CAL E., VILLAR, J. (2010) A soft computing method for detecting lifetime building thermal insulation failures. In Integrated Computer-Aided Engineering, Vol. 17, Issue 2 , pp. 103-115, IOS Press.

SELYE, H. (1956) The Stress of Life. McGraw-Hill.

STEENBERGEN, W. (2005) Rationalizing Dispute Resolution: from best alternative to the most likely one, Proceedings of 3rd ODR Workshop, Brussels.

THOMAS, K., KILMANN, R. (1974) Conflict and Conflict Management. Available at http://www.kilmann.com/conflict.html <last accessed July, 2012> 
VIZER, L. M., ZHOU, L., SEARS, A. (2009) Automated stress detection using keystroke and linguistic features: An exploratory study. International Journal of Human-Computer Studies, 67(10):870-886.

ZARGARI, S. A., SIABIL, S. Z., ALAVI, A. H. AND GANDOMI, A. H. (2012) A computational intelligence-based approach for short-term traffic flow prediction. Expert Systems, 29: 124-142. doi: 10.1111/j.1468-0394.2010.00567.x. 


\section{Biographies}

\section{Davide Carneiro}

Davide Carneiro is a fellow researcher at the CCTC (Computer Science and Technology Center), at the Department of Informatics, University of Minho, Braga, Portugal. He is currently finishing his $\mathrm{PhD}$, in which he worked under a joint Doctoral Programme in Computer Science that aggregates three top Portuguese Universities. He develops scientific research in the field of Artificial Intelligence, namely in Multi-agent Systems, Genetic Programming and Casebased Reasoning applied to the Legal field and Ambient Intelligence. He is the coauthor of several publications in this field, including international journals, book chapters and conference proceedings. In 2008 he has been awarded the TLeIA08 a National Award for Artificial Intelligence projects attributed by the Portuguese Artificial Intelligence Association, and in 2009 he has been awarded an Academic Merit Scholarship by the Portuguese Government.

\section{Marco Gomes}

Marco Gomes is a researcher at the CCTC (Computer Science and Technology Center), at the Department of Informatics, University of Minho, Braga, Portugal. He is currently enrolled in Doctoral Program on Informatics and develops scientific research in the field of Artificial Intelligence. He is the author of publications in conference proceedings and journals in the fields of Online Dispute Resolution and Ambient Intelligence.

\section{Ângelo Costa}

Ângelo Costa received the B.Sc. degree in Informatics Engineering, the M.Sc. in Informatics Engineering and Ph.D. in Biomedical Engineering in 2013 from the University of Minho. Currently he is a researcher at the CCTC (Computer Science and Technology Center) and the AAL4ALL project. He develops scientific research in the field of Artificial Intelligence, namely Cognitive Assistants and Multi-Agent Systems. Currently he is one of the main developers of cognitive assistants for mobile platforms.

\section{Paulo Novais}

Paulo Novais is an associate Professor of Computer Sciences at the Department of Informatics, in the University of Minho, Braga, Portugal and researcher at the CCTC (Computer Science and Technology Center) in which he is the coordinator of the Intelligent Systems Lab. From the same university he received a $\mathrm{PhD}$ in Computer Sciences in 2003 and his Habilitation in Computer Sciences in 2011. He develops scientific research in the field of Artificial Intelligence, namely Knowledge Representation and Reasoning, Machine Learning and Multi-Agent Systems, with applications to the areas of Law and Ambient Intelligence. He is the 
co-author of over 120 book chapters, journal papers, conference and workshop papers and books. He is Vice-president of APPIA, the Portuguese Association for Artificial Intelligence.

\section{José Neves}

Jose Neves is Full Professor in Computer Science at the University of Minho, in Braga, Portugal, since 1983. Jose Neves is the Deputy Director of the Artificial Intelligence (AI) Group at the same university. He received his $\mathrm{PhD}$ in Computer Science from Heriot Watt University, Edinburgh, Scotland, in 1983. His current research interests are in the areas of knowledge representation and reasoning and evolutionary intelligence, aiming to construct dynamic virtual worlds of complex symbolic entities that compete against one another, in order to solve complex problems. 